\title{
Study and evaluation of VolP Scalability Performances
}

\author{
Ayoub Bahnasse \\ LIMIE Laboratory \\ Centre EI Jadida, Groupe ISGA \\ El Jadida, Morocco
}

\author{
Zakariae Malainine \\ LIMIE Laboratory \\ Centre EI Jadida, Groupe ISGA \\ El Jadida, Morocco
}

\author{
Hamza El Azzaoui \\ LIMIE Laboratory \\ Centre El Jadida, Groupe ISGA \\ El Jadida, Morocco
}

\begin{abstract}
The telecommunications industry is currently moving towards the trade of Internet services. However, with the extension in terms of enterprises sites, the quality of transported traffic can be influenced. Given that the nature of deployed application vary periodically and become more and more demanding in terms of delays, the scalability need can lead to a dysfunction of the latter. In this paper, we will measure and evaluate the impact of multiples clients on the performances of the network and the transported applications. This study was done under the Riverbed Modeler simulator. The traffics used for the simulations is Voice over IP (VoIP). The evaluation criteria are on the jitter, the end-to-end delay, and the VoIP loss rate.
\end{abstract}

\section{General Terms}

Enterprise infrastructure deployment.

\section{Keywords}

VoIP, Corporate infrastructure, performance evaluation, OPNET Modeler.

\section{INTRODUCTION}

In recent years, Voice over IP (VoIP) [1] has become very popular. A large majority of modern companies use it. Indeed, VoIP has many advantages. VoIP (Voice over IP) is the ability to use TCP / IP networks as a support for voice communications (telephone calls, radios ...), which includes coding and quality of service (QoS) [2]. The encoding defines the transformation of a flow of analog speech into a computer stream. QoS defines the conditions for this speech flow digitized complies with the constraints of an interactive voice communication. In comparison with traditional telephony, IP telephony has several advantages [3]. Among them:

\section{- $\quad$ Reduce costs}

- Standardize equipment

- Centralize the management of all communications of the company: triple play network (Voice, video, data)

- Improve call management

- Increase business productivity

Despite all the advantages presented above, there are risks and inconveniences. These risks lie essentially at the level of security and the network. In fact, IP telephony is exposed to the risks associated with internet like lines hacking or data theft [4]. In 2017, the European mobile VoIP market was predicted to reach a size of 14 billion U.S. dollars. Many businesses are adopting VoIP in order to reduce their phone bills and unified communications platforms - combining phones, faxes, web conferencing, and other communications services - are emerging to capture this market [5]. The use of VoIP caused a very significant loss of revenue for telephone network operators. These operators compensated for this loss with new revenues from subscriptions for Internet services and the explosion in demand for mobiles. However, many developing countries have restricted the use of VoIP to protect incumbent operators whose revenues from international communications constituted a high percentage of their resources. The rest of the paper is organized as follows, in the section 2 we will discuss the SIP signaling protocol. In section 3 we will discuss the most recent related works. In section 4 we will present the simulation environment. In section 5 we will present and discuss obtained results. The conclusion will be presented in section 6 .

\section{SIP SIGNALING PROTOCOL}

Signaling protocol SIP stands for Session Initiation Protocol [6]. It is an open standard protocol for multimedia telecommunications (sound, message, video, etc.). It is currently the most used protocol for VoIP. It is not only for VoIP, but also for many applications such as instant messaging, video telephony, virtual reality or even video games. SIP was designed to establish, modify and terminate multimedia sessions. It intervenes in different phases of the call:

- Location of the user: determination of the terminal system to be used for communication

- Availability of the user: determination of the will of the called party to engage in a communication

- User capacities: determination of the support and the support parameters to be used

- Session establishment: establishment of the session settings at both caller and called

- Session management: includes session transfer and termination, changing session parameters, and invoking services.

Elements of the SIP network are:

- User Agent; this is an application on a user equipment that sends and receives SIP requests

- $\quad$ Registrar; user registration software server and saves the location (@IP and URI) of the User Agent in a DB

- The Proxy server; used to connect 2 customers who do not know their location and ask the Registrar for the location of the clients

- Redirection server; helps locate the terminals by providing an alternative address to which the requested terminal can be attached.

Performing a call using the SIP protocol is illustrated through the figure 1 


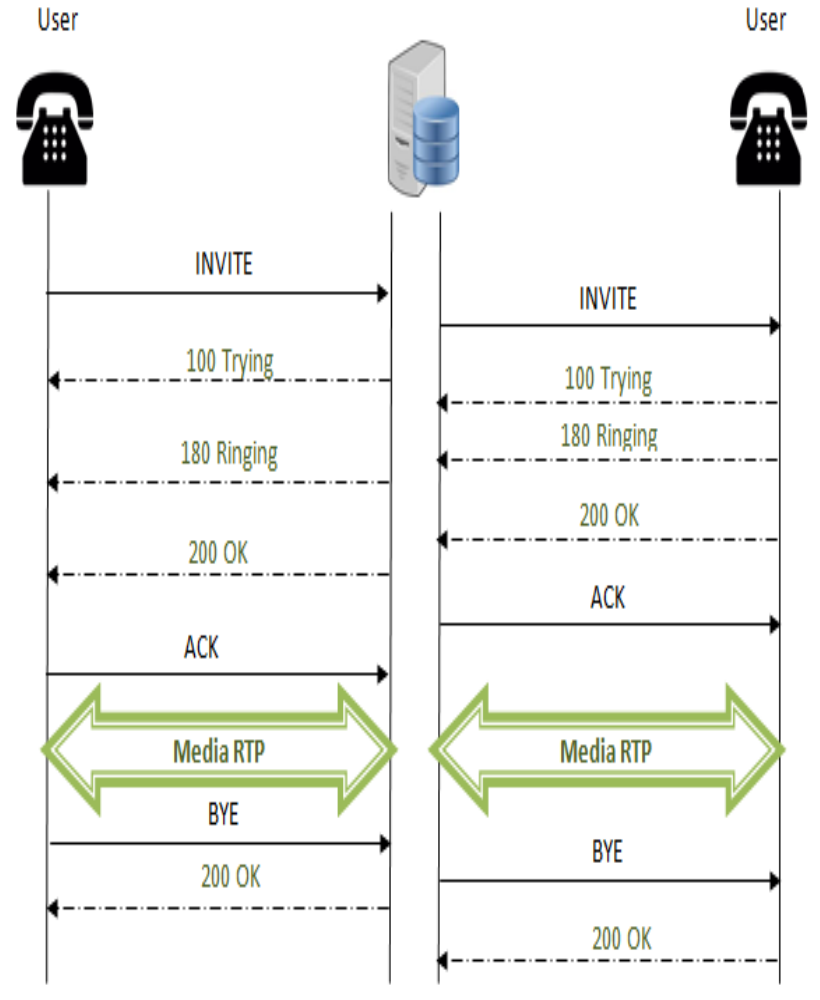

Fig 1: Operation of SIP protocol

\section{RELATED WORKS}

Several works have been done for the evaluation of VoIP performance in computer networks.the work [7] evaluated the performance of the SIP and H.323 signaling protocols and their impact on the performance of homogeneous and heterogeneous wireless networks. The MIPv6 mobility protocol was used in the simulations. The results obtained showed the efficiency of the SIP protocol compared to H.323 in terms of call setup time, and the efficiency of H.323 in terms of reduced time and low loss rate.the work [8] evaluated the scalability of the OSI network layer tunneling protocols using VoIP as an application, the study showed that the tunnel layer has a negative impact on VoIP, so the authors showed that boosting degrades network performance. The two previous works have not been done taking into account the feedback in terms of the number of users. The work [9] was done by increasing the number of users and by varying the type of VoIP codec (GSM, G.729, and G.711) the study showed that the nature of the codec can also vary the quality of VoIP. The authors have taken a maximum of 25 users, however, in a corporate or campus network, the number of VoIP users is much larger than that.

\section{SIMULATION ENVIRONMENT}

OPNET Modeler [10] is well known in the industry for network modeling and simulation. It allows draw and study communications networks, devices, protocols, and applications with ease and scalability; it is also used by the most successful technology companies to accelerate their research and development processes. The object-oriented approach associated with integrated graphical editors from Modeler simplifies the composition of networks and equipment. This makes it easy to map your information system to your model. Originally developed at the Massachusetts Institute of Technology (MIT) and marketed in 1987 as the first network simulator, OPNET Modeler continues to be the state-of-the-art reference with the following key features:

- Modeler is the most scalable and scalable engine of simulation engines. For wired and wireless network models, it allows using simulation runtimes that use acceleration techniques.

- Hierarchical network models support complex topologies with unlimited number of nested subnets.

- It allows launching scenarios at the seeing of the projects in order to be able to compare the different architectures. Full support for the realization of protocols. More than 1000 functions are included and the libraries provide the support for the realization of the protocols.

- Comprehensive library including multi-tier applications, voice, http, TCP, OSPF IP, BGP, EIGRP, RIP, RSVP, Frame Relay, FDDI. All these standards models are provided as finite state machine (FSM) with the source code.

Our model simulated by OPNET Modeler of the VoIP, takes as input or as a system of telecommunication to evaluate the scalability of the signaling protocol SIP, acting on the three settings: Call Setup Time, throughput, MOS value, and Queuing delay using Signaling protocol SIP.

The network on which the simulations were performed is shown in this figure 2

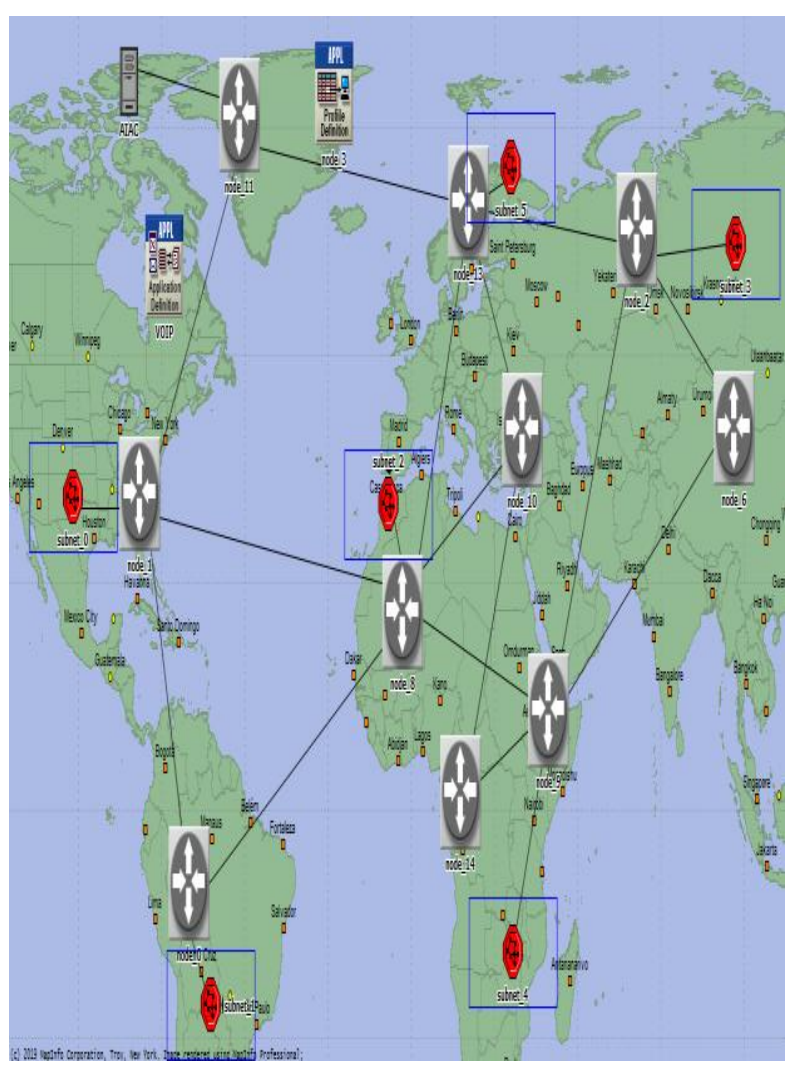

Fig 2: Model of experimentation 


\subsection{Evaluation parameters}

Used evaluation parameters are shown on Table1.

Table 1. Evaluation criteria

\begin{tabular}{|c|c|}
\hline Criteria & Designation \\
\hline $\begin{array}{l}\text { Call Set-up } \\
\text { Time }\end{array}$ & $\begin{array}{l}\text { Is the period of time elapsing from the sending } \\
\text { of a complete destination address (target } \\
\text { telephone number) to the setting up of a call to } \\
\text { the receiving terminal (sec) }\end{array}$ \\
\hline $\begin{array}{l}\text { End to end } \\
\text { delay }\end{array}$ & $\begin{array}{l}\text { Is given by the ratio of the time when the data is } \\
\text { received minus the data transmission time } \\
\text { divided by the number of data packets received. } \\
\text { It is a significant parameter affecting the user's } \\
\text { satisfaction with the application.1- It allows us } \\
\text { to have several important functions to the users, } \\
\text { such as: the digitization, the coding, the } \\
\text { decoding of the data and also their display to } \\
\text { the users (sec) }\end{array}$ \\
\hline $\begin{array}{l}\text { MOS(Mean } \\
\text { opinion } \\
\text { score ) } \\
\text { values }\end{array}$ & $\begin{array}{l}\text { This parameter is used to measure the quality of } \\
\text { the voice data, using the arithmetic mean of all } \\
\text { the results about this for each client to give an } \\
\text { average. Using an evaluation system, one can } \\
\text { retrieve the results concerning the quality of the } \\
\text { sound and the coherence of the result }\end{array}$ \\
\hline Loss rate & $\begin{array}{c}\text { A loss rate is the frequency with which losses } \\
\text { are incurred }\end{array}$ \\
\hline $\begin{array}{l}\text { Queuing } \\
\text { delay }\end{array}$ & $\begin{array}{l}\text { The sum of the delays between the request for } \\
\text { service and the establishment of a circuit to the } \\
\text { called data terminal equipment (sec) }\end{array}$ \\
\hline Throughput & $\begin{array}{l}\text { concerns the amount of data transmitted in a } \\
\text { given period of time (bits } / \mathrm{sec})\end{array}$ \\
\hline
\end{tabular}

The next section presents results of our simulation.

\section{RESULTS AND DISCUSSION}

\subsection{Call setup time}

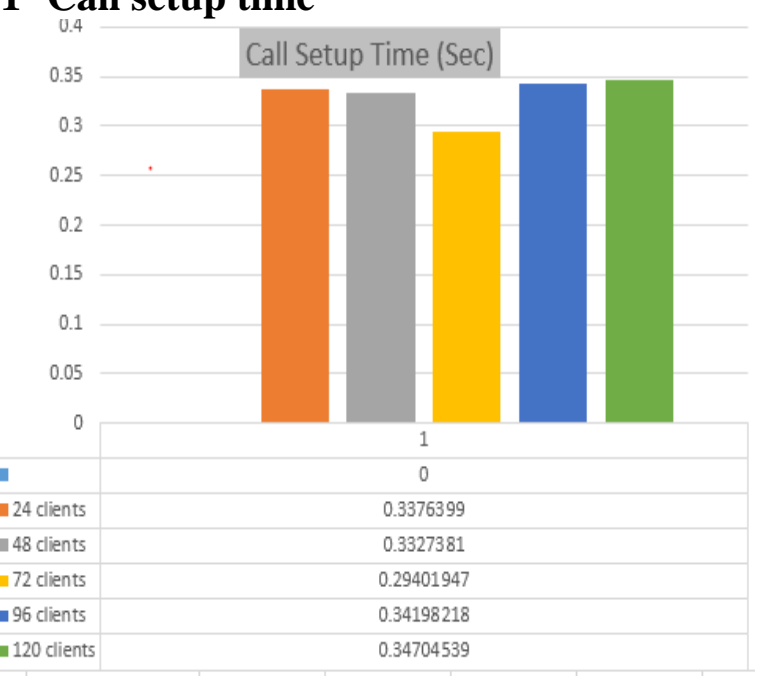

Fig 3: Call Set-up Time
Figure 3 illustrate the overall length of time required to establish a call between several users. It seems that the Call Set-up Time is almost the same for each slice of number we chose, so we can say that this parameter can be degraded only when we reach a large number of clients. The rate of progression of the duration of establishment is of the order of $0.001 \%$ on average between different intervals of clients.

\subsection{End to end delay}

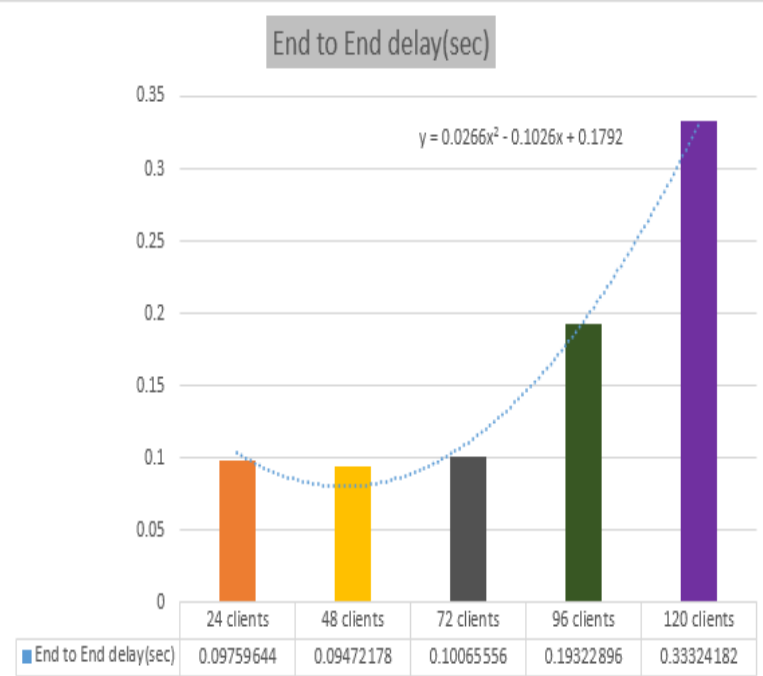

Fig 4. End to end delay

Figure 4 shows the end to end delay, it is the factor that has let us see a delivery time a packet on our network from the source to the destination. We note that this end-to-end delay is almost the same for customer numbers that do not exceed 72 customers. We conclude that when the number of customers becomes important, the end-to-end delay starts to increase in an evolutes way. We conclude that when the network is busier, the quality or the performance of the endto-end delay will be degraded. The function that governs this progression is given by the formula: $\mathrm{y}=0.0266 \times 2$ $0.1026 x+0.1792$

\subsection{MOS (Mean opinion score) values}

Figure 5 gives us an idea of the quality of the calls, so the MOS is an important tool that will test the VoIP to determine the problems that affect the data flow. It gives VoIP testing a number value as an indication of the perceived quality of being transmitted. VoIP calls are in the 3.5 to $4.2 \mathrm{MOS}$ range.

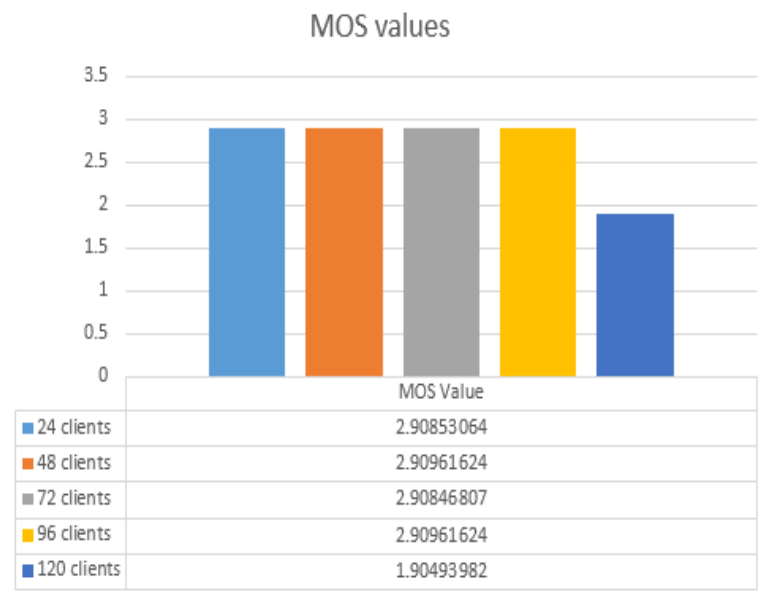

Fig 5: Values of Mean opinion score 
Figure 6 shows the different values of MOS concerning the quality of the voice and the interpretations:

\begin{tabular}{|c|c|}
\hline Maximum for G.711 codec & 4.4 \\
\hline Very satisfied & $4.3-5.0$ \\
\hline Satisfied & $4.0-4.3$ \\
\hline Some users satisfied & $3.6-4.0$ \\
\hline Many users dissatisfied & $3.1-3.6$ \\
\hline Nearly all users dissatisfied & $2.6-3.1$ \\
\hline Not recommended & $1.0-2.6$ \\
\hline
\end{tabular}

\section{Fig 6: Interpretation of MOS values}

From the obtained results in our simulation and the interpretations of the table in Figure 6, we can say that almost all clients are not satisfied with the quality of VoIP. So we see that as soon as the number of clients increases, the quality of VoIP is decreasing.

\subsection{Loss rate}

Figure 7 illustrates the loss rate. In our simulation the loss rate is small, which means that the transmission quality of a packet is good, as long as the losses are negligible. Thus we notice that the loss rate increases when we increase the number of customers. A percent of $7.75 \%$ was achieved on 120 clients scenario, this score is not acceptable to provide a good telephony quality.

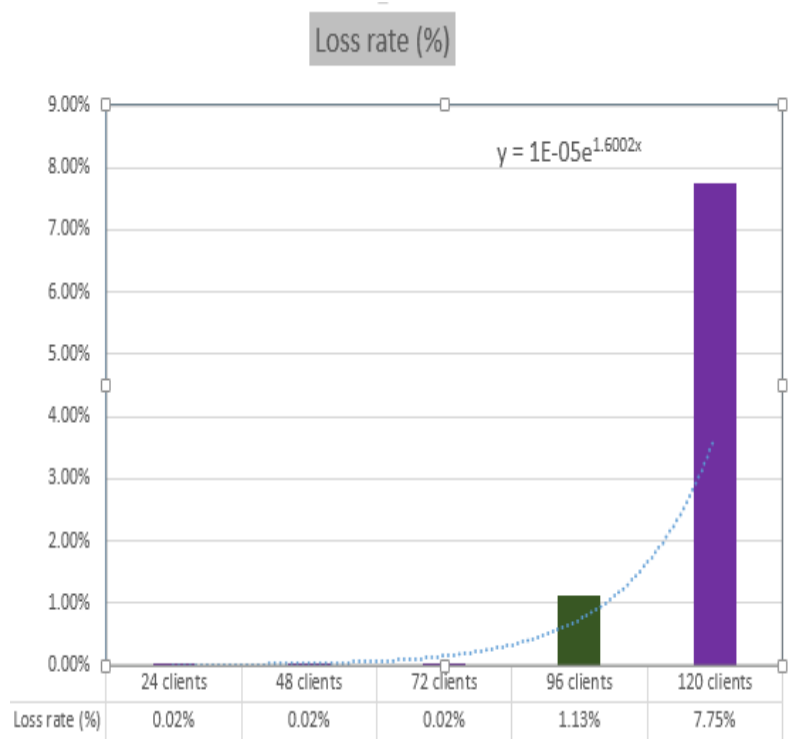

Fig 7: Loss rate

\subsection{Queuing delay}

The Queuing Delay allows us to learn about the time elapsed between the end of the signaling by the initiator of the call and the arrival of a ringtone in the receiver of the call.

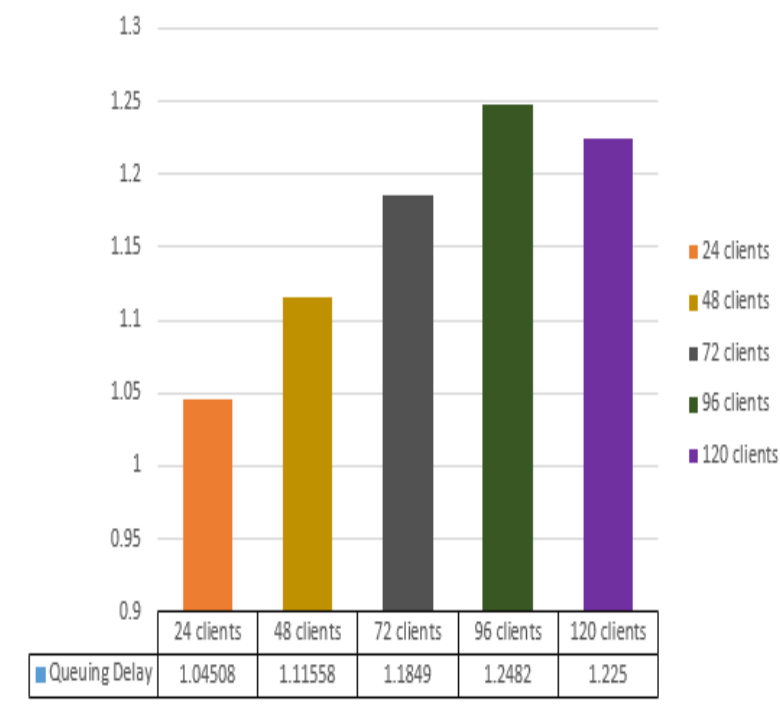

Fig 8: Queuing Delay (sec*10-05)

\subsection{Throughput}

The throughput is the amount of data transmitted per second. It is calculated by dividing the file size to the required time. Figure 9 shows that the size of transmitted files increases with each increase in the number of clients, following the equation: $\mathrm{y}=317.66 \mathrm{x}-3.4878$

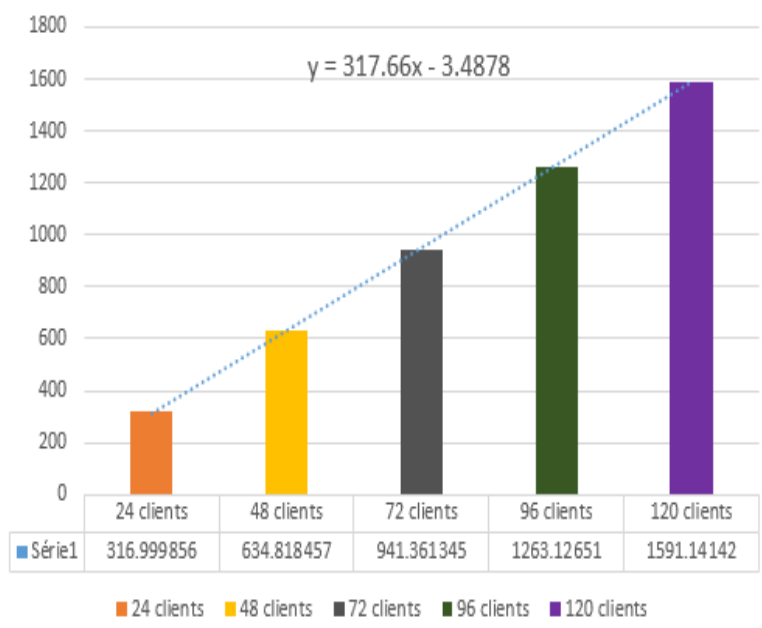

Fig 9: The throughput

\section{CONCLUSION}

In this paper we evaluated the performance of VoIP in large scale networks by increasing the number of users. the study was done under the OPNET Modeler simulator, taking into consideration several evaluation criteria: call set-up delay, end-to-end delay, MOS score, throughput, queue delay. the study was done by increasing the number of users using the SIP signaling protocol. the results can be used for sizing future networks. In the next job we will size the network of our group of ISGA schools with video conferencing applications, databases, and database traffic. 


\section{ACKNOWLEDGMENTS}

This work is a validation of a mini project carried out by the engineering students Zakariae Maalainine and Hamza Azzaoui in ISGA El Jadida, supervised by Dr A. Bahnasse. We address our sincere thanks to the director $\mathrm{Dr} \mathrm{A}$. Outzourhit for encouraging us to lead this work and to our school for providing us necessary tools to success this experience.

We would like to thank the editor and the anonymous reviewers for their comments that contributed to the improvement of the work.

\section{REFERENCES}

[1] Alharbi, A., Bahnasse, A., \& Talea, M. (2017). A Comparison of VoIP Performance Evaluation on different environments Over VPN Multipoint Network. International Journal of Computer Science and Network Security (IJCSNS), 17(4), 123.

[2] A. Bahnasse, N. El Kamoun, "Policy-Based Smart Adaptive Quality of Service for Network Convergence", International Journal of Computer Science and Information Security, vol. 13, no. 3, pp. 21-27, 2015.

[3] Rojas, H., Renteria, R., Luque, E. N., Peralta, M., \& Merma, J. L. (2018). Proposal to Implement Low Cost Digital Communication Using VoIP Technology, a Case Study. International Journal of Future Computer and Communication, 7(3).

[4] Volodina, E., Aziz, A., Rathgeb, E. P., \& Hossfeld, T. (2018, August). Application of Visual Analysis to Detect and Analyze Patterns in VoIP Attack Traffic. In 2018 17th IEEE International Conference On Trust, Security
And Privacy In Computing And Communications/12th IEEE International Conference On Big Data Science And Engineering (TrustCom/BigDataSE) (pp. 260-268). IEEE.

[5] Global mobile VoIP market size by region 2014-2024 Statistic. (2019). Retrieved from https://www.statista.com/statistics/691602/globalmobile-voip-market-size-by-region/

[6] Bensalah, F., El Hamzaoui, M., \& Bahnasse, A. (2018). Behavior study of SIP on IP multimedia subsystem architecture MPLS as transport layer. International Journal of Information Technology, 10(2), 113-121.

[7] Khiat, A., El Khaili, M., Bakkoury, J., \& Bahnasse, A. (2017, May). Study and evaluation of voice over IP signaling protocols performances on MIPv6 protocol in mobile 802.11 network: SIP and H. 323. In 2017 International Symposium on Networks, Computers and Communications (ISNCC) (pp. 1-8). IEEE.

[8] Bensalah, F., El Kamoun, N., \& Bahnasse, A. (2017). Analytical performance and evaluation of the scalability of layer 3 tunneling protocols: case of voice traffic over IP. IJCNS International Journal of Computer Science and Network Security, 17(4), 361-369.

[9] BAHNASSE, A., BADRI, A., LOUHAB, F. E., TALEA, M., KHIAT, A., \& PANDEY, B. (2018). Behavior analysis of VoIP performances in next-generation networks. International Journal of Engineering \& Technology, 7(3.15), 353-359.

[10] Lu, Z., \& Yang, H. (2012). Unlocking the power of OPNET modeler. Cambridge University Press. 